\title{
Airborne Laserscanning in Archaeology: Maturing Methods and Democratizing Applications
}

Rachel Opitz 1 ,*

Email: ropitz@usf.edu

Center for Virtualization and Applied Spatial Technologies (CVAST) and Department of Anthropology, University of South Florida, Tampa, FL, 33620 USA

\section{Abstract}

Archaeologists have been using airborne laserscanning (ALS) for over a decade in projects ranging from heritage management schemes for post-industrial uplands in the UK or state-managed forests in Germany to research on cities now obscured by tropical jungle canopy in Central Mexico. The basic methods for the analysis and interpretation of this data have matured considerably and data is increasing available. Building on this increasing accessibility and an established basic methodology, archaeologists are addressing a growing variety of ground conditions and research and heritage management objectives through this technology. With this diversification comes the need to adapt the basic methods used to new landscapes and types of archaeological remains, and to integrate the practice of working with ALS with diverse fieldwork and research practices.

\section{Keywords}

Airborne laserscanning/lidar

Topography

Archaeological survey

Aerial archaeology

Landscape archaeology

\section{Introduction}

This chapter aims reviews the current state of practice in the use of Airborne Laser Scanning (ALS), or LiDAR, in archaeology, highlighting areas of ongoing research and open questions where further work is needed. Happily, the use of Airborne Laser Scanning as a method has reached a state of relative maturity. It is broadly accepted as a basic source of extensive and detailed topographic data (Opitz and Cowley 2012) and is widely used to promote the integrated study of past and present land use and landscape modification in archaeology. The general workflow is one of data acquisition, classification, surface and bare earth terrain model creation, visualization, and interpretation. Different projects and applications may introduce variations at some or all of these steps to suit their needs, but the general workflow remains the same.

\section{AQ1}

Looking at the specific steps in the processing chain, the current classification methods used throughout the ALS industry produce results that can be used in archaeological research. Several papers have emerged comparing different visualization methods and making recommendations for their use under various archaeological and ground cover circumstances (Štular et al. 2012; Bennett et al. 2012). Software toolkits collecting the most commonly used Digital Terrain Model (DTM) visualizations, and targeted for an archaeological audience, have been produced, and are 
available through the ArchaeoLandscapes Europe network ( http $/ /$ www.arcland.eu/outreach/software-tools ) or directly from individual or institutional creators (RVT — http://iaps.zrc-sazu.si/en/rvt\#v and LiVT-

http:/sourceforge.net/projects/livt/ ). In short, the strictly methodological work in this domain has moved from the general case to special circumstances in which advanced processing of the data or customized visualizations are needed.

Having said that the methodology is more or less settled, if we broaden out our definition to include the fieldwork routines, image interpretation, and map-reading, then we see a rapidly evolving methodology among a growing ALSusing archaeological community. This second level of methodological development is not about the technical developments that interest specialists, but rather about the use of the data provided through this technology by the broader archaeological community. In this sense, the practice of working with ALS in archaeology has moved decisively off the desk and out into the field, and its integration into fieldwork practice is an important area of innovation. The democratization of the use of ALS in archaeology, as it moves from a specialist tool to one integrated into many projects, as are aerial photographs and maps, is the driver behind most current methodological progress.

The impact of the availability of ALS data to a growing pool of researchers, and the subsequent re-focus on topography as a source of archaeological information, raises a number of interesting questions about specific classes of features and the impacts of more recent land use. These points have been raised elsewhere in this volume, notably by Limp (Chap. $x$ ) in his discussion of the broader impacts of High Density Survey and Measurement, of which ALS is a subset (see also Opitz and Limp 2015 ). Along similar lines, the use of ALS is driving an interesting expansion in the practice of image interpretation, as the terrain model visualizations are just unfamiliar enough to force careful image reading, while being just familiar enough to encourage many archaeologists to undertake their own interpretive work.

\section{AQ2}

\section{Established Methods and Practices for Archaeological ALS}

\section{Data Acquisition}

The acquisition of ALS data, while generally not carried out by archaeologists, does require that they involve themselves in the specification of the survey parameters, or - in the case of pre-existing datasets - that they are aware of the limitations imposed by the survey parameters chosen by someone else. The desired spatial resolution of the final data product, the number of returns per pulse, the tradeoff between aerial coverage and resolution (essentially a choice in terms of helicopter vs. fixed wing platform, with implications for cost and survey area size), the scan angle, and occasionally the instrument choice must be specified. For most archaeological applications, an $\mathrm{x}$-y planimetric resolution of $8 \mathrm{pts} / \mathrm{m} 2$ is considered to be the minimum for archaeological work, with $16 \mathrm{pts} / \mathrm{m} 2$ or greater being a desirable range. Smaller scan angle ranges, minimizing returns lost to vegetation are likewise considered desirable, with the exception of mountainous landscapes or areas of steep-sided valleys or canyons, where a larger scan angle might help avoid occluded areas. The number of returns per pulse is perhaps less crucial as modern instrumentation generally support the minimum of four returns per pulse recommended for archaeological surveys. The general guidelines for data acquisition can be found in Opitz and Cowley (2012, Chap. 2), and the recommendations remain largely unchanged.

\section{Classification Routines}

The method for the classification of ALS point cloud data to remove vegetation and reveal the 'bare earth' and traces of archaeologically relevant topography is well established for most situations (Fig. 1), and the areas where it is likely to be problematic are known. Broadly, areas with low scrub vegetation, low scrub within a multistory canopy, and close coniferous plantation remain problematic, as do areas with large amounts of surface debris e.g. boulder fields. There are two approaches taken to improving classification in these cases. First is the collection of full waveform data. The number of projects using full waveform data remains comparatively small. Where it is employed, the echo width of each peak in the signal is used to help distinguish between low scrub, sloping terrain, and terrain returns (Chauve et al. 2007). The 
improved classification achieved using echo width is seen as the main advantage of full waveform over discrete return data. Second, are alternative classification routines that are generally more computationally expensive, but may be effective for treating small areas (e.g. Brodu and Lague 2012; Opitz and Nuninger 2014). These alternative approaches to classification are discussed below, in the Special Cases in Classification section.

Fig. 1

Profile view of a classified ALS point cloud. Terrain returns are shown in orange and vegetation returns in green

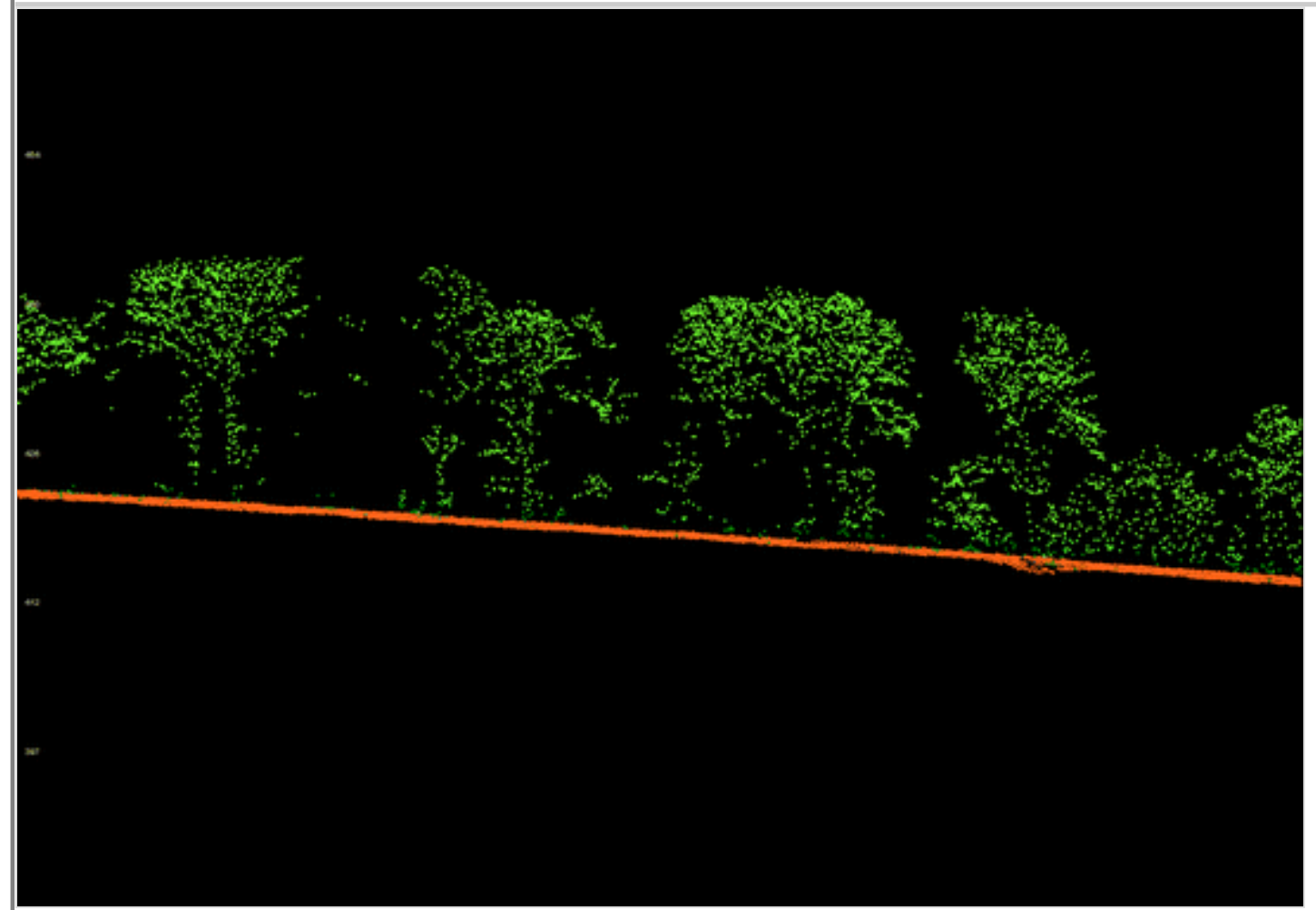

Outside of these environments, the algorithms implemented in industry standard software packages including Terrascan ( www.terrasolid.com ) and LAStools ( http://rapidlasso.com/lastools/ ), and in the open source MCC-Lidar ( http://sourceforge.net/projects/mcclidar/ ) will produce terrain models of sufficient quality to support archaeological interpretation and to be the basis for a survey project. Projects receiving pre-classified data from larger industry providers will likely be working with the results of the modified Axelsson algorithm (Axelsson 1999) implemented in Terrascan, the dominant software package for companies in the business of ALS data acquisition. As LAStools increased in popularity in the archaeological community, with its lower cost compared to Terrascan and (in this author's opinion) more user-friendly implementation, its classification routine is increasingly employed by those producing their own classifications from a raw point cloud, or reclassifying subsets of their data in hopes of improved results.

\section{Visualizations}

The majority of ALS related methodological discussion in recent years has centered in the panoply of visualization methods available, and how to select the most effective ones for a given type of landscape or features. Archaeological ALS DTM visualizations are dominated by simple hillshades, local relief models (and variants thereon) (Hesse 2010), sky view factor (and variants thereon) (Kokalj et al. 2011), and elevation ramps. Broadly, hillshades are beneficial in that they highlight low reliefs by simulating raking light from a single direction across the terrain surface. Sky view factor is useful for identifying small pits and depressions, or narrow areas of relief, as it highlights the difference between tightly enclosed spaces (where one would have little ability to see the sky) and topographically prominent ones (with clear 
views all around). Elevation ramps, while only showing anomalies well in exceptionally flat terrain, or by stretching the available values to match the elevation range present in a small localized area, are useful in providing an absolute sense of the size of anomalies. These visualizations are commonly combined in layers, and different combinations are employed depending on the circumstances (Fig. 2).

\section{Fig. 2}

Terraces and field systems in Gozo are visualized using a combination of Sky View Factor (16 look directions, $10 \mathrm{~m}$ radius) and an elevation ramp. These layers provide a sense of absolute elevation change while highlighting terrace edges and boundary walls. (Data provided with kind permission of the University of Malta FRAGSUS team The Digital Terrain Model used in the process of model building was derived from the LiDAR data made available through an agreement signed between the University of Malta and the Malta Environment and Planning Authority in 2013. We acknowledge the source: ERDF LIDAR data, 2012, ERDF156 Developing National Environmental Monitoring Infrastructure and Capacity, Malta Environment and Planning Authority)

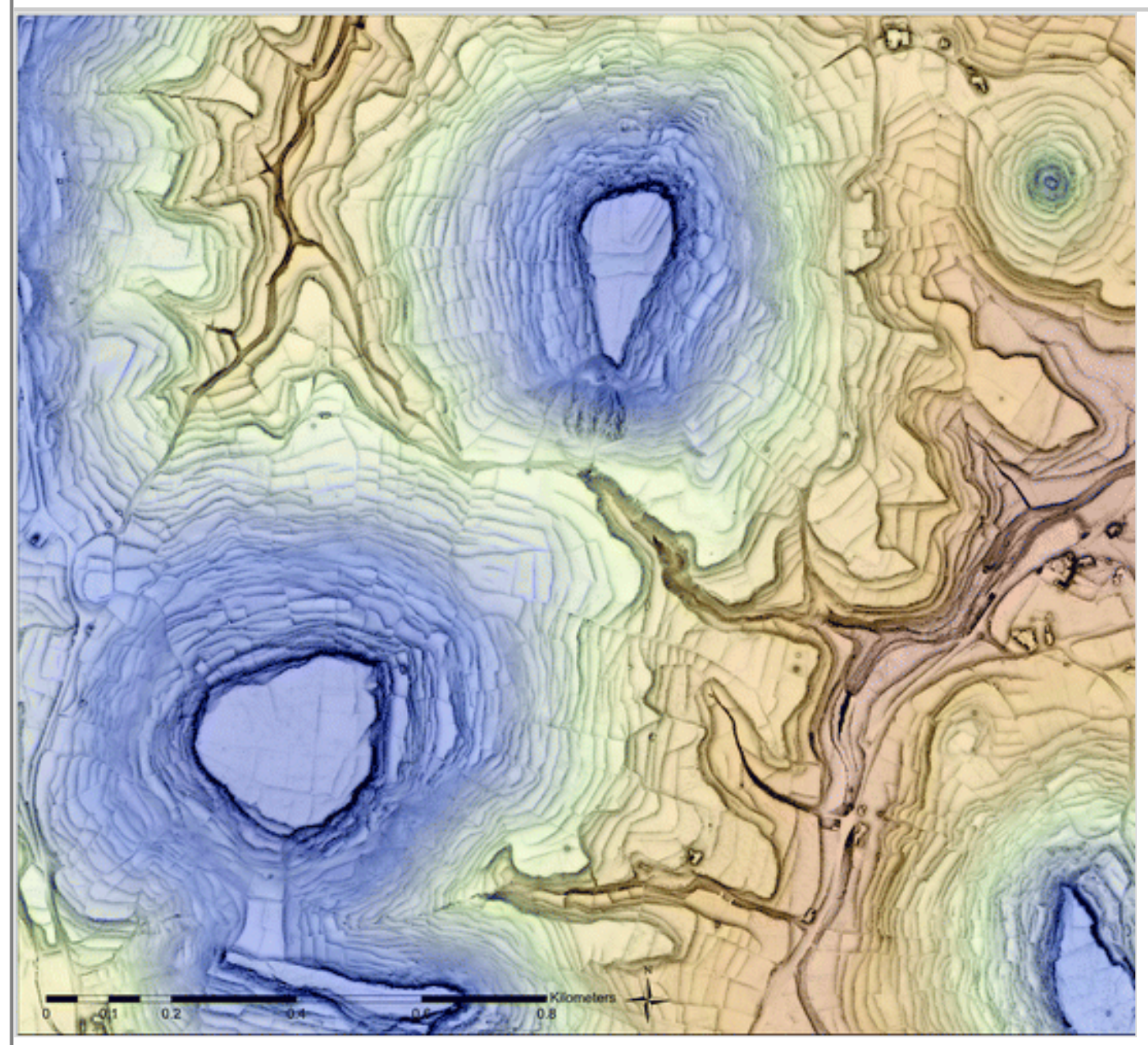

At its core the problem with visualizations is that while producing 16 different renderings of each part of the landscape is relatively simple and may be automated, looking through sixteen different visualizations for each chunk of landscape is not feasible for most projects. Somehow, an individual interpreter or team must select a basic subset of all possible visualizations with which they will work for each project. In multi-interpreter teams, the likelihood of achieving some level of consistency between individuals will be increased if everyone works from the same set of visualizations. Best practice has emerged as selecting around three visualizations to be used in combination. This represents a compromise between techniques that do well at low relief, techniques that distinguish open and closed, and techniques not dependent on 
lighting/illumination, without requiring interpreters to engage with an overwhelming number of visualization combinations. This question has been discussed by both Štular et al. (2012) and Bennett et al. (2012) in detail and suggestions for good combinations of visualizations for certain ground cover conditions and types of archaeological features are made in these articles.

\section{Ongoing First Level Methodological Development}

\section{Special Cases in Classification: Low Scrub}

Low, dense vegetation masking both the detail of surface topography and any low standing structures e.g. field boundary walls is a longstanding problem in ALS-driven archaeological landscape studies. Two problems converge in situations where the ground cover is dominated by low scrub. First, at the moment of data collection very few returns will reach the ground and return to the sensor, as energy is scattered by the complex canopy structure of this vegetation. Second, classification algorithms dependent on changes in slope or curvature between neighboring points struggle to differentiate between returns from low scrub and those from small changes in the topography. The result is an entire class of land use where archaeological visibility is remarkably poor, though in long-standing scrub areas preservation is likely to be better than average. While little experimental work has been carried out, lower flying elevation, smaller beam footprints, a different wavelength outside the NIR range reflected strongly by vegetation and a smaller scan angle range are all methodologically feasible possibilities for improving the number of returns from the ground in areas with this kind of ground cover.

Here we can touch briefly on the rapidly evolving suite of UAV ALS platforms. Notably, these platforms may transform the quality of data collection in scrub areas, as they facilitate lower flying elevations and smaller footprints, which should improve data quality (see Nex and Remondino 2014 for an overview of applications and future directions). UAV ALS platforms will likely produce data requiring processing strategies more like those used for mobile lidar or Terrestrial Laserscanning Survey (TLS). In particular, given the fine resolution of the data relative to the precision available from the combined DGPS/IMU platforms deployable on a UAV, tight alignment between flight strips is likely to remain a challenge (Watts et al. 2012). As with TLS survey, the quality of the alignments between individual scans are often more than sufficient for the reliable interpretation of archaeological features, but larger sets of scans/flightstrips may result in propagating errors to the point that visual mis-alignments interference with the identification of features.

Barring fundamental changes in data collection strategies, improved classification of the point cloud following the kinds of methods employed for the classification of TLS scenes (Brodu and Lague 2012) have been pursued by the author (Opitz and Nuninger 2014). Classification strategies that depend on variations in local density, roughness, and 3D rather than profile curvature, measured across multiple scales have proven, in limited tests, to produce better results in complex scenes with low scrub and standing remains or surface microtopography.

\section{Special Cases in Classification: Stony Surfaces}

Closely related to situations in which a landscape is dominated by low scrub that masks the archaeological topography and standing remains of interest, are 'cluttered' landscapes where surface debris including boulders and large stones are common. Here we face several complications. First, the stones themselves sometimes form part and parcel of the archaeology, as they are gathered into field boundaries, small cairns, and other forms. Second, there is zero penetration to the ground - any removal of returns from the stones will results in a visually jarring gap in the terrain model. Therefore the aim of this kind of classification of stony surfaces into 'surface objects' and 'background terrain' in not to remove the stones from the digital model, but to highlight or obscure them, aiding in the visual interpretation of topography and surface features. Further, one may attempt to separate individual or small clusters of surface debris from larger clusters or alignments, essentially moving to an object oriented classification approach. Software including eCognition ( www.ecognition.com/) supports this kind of classification routine. Barring a formally object oriented approach, these 
regions might be flagged as concentrations of higher variability in local curvature or roughness — metrics paralleling those used to remove vegetation from low scrub scenes.

As with low scrub classification, the size at which the kernel is set is critical to the effective separation of different classes of features. The kernel size must be calibrated to a scale at which surface stones are showing a high degree of variability but the background topography is not. As with vegetation classification routines, the results of this kind of classification will not be $100 \%$ accurate, and $80 \%$ accuracy in separation of the surface scatters of stones and background terrain would be considered a good result.

\section{Special Cases in Visualization: Direct Viewing of Point Cloud Data}

Most archaeologists working with ALS data take the Digital Terrain Model and Digital Surface Model(DTM and DSM respectively) as their starting points, and build additional visualizations of the data on top of these models. The DTM and DSM, of course, are themselves abstractions of the point cloud data (itself an abstraction of the waveform data) that is the native format for ALS. In many cases the visualizations based on the DTM and DSM represent the best choice for interpretive work, as features appearing in them look somewhat familiar to those with experience reading aerial imagery or topographic maps. However, under some circumstances it is useful to engage directly with the point cloud data. For example, in situations where standing structures in overgrown areas, particularly where these structures have multiple parts e.g. a ruined castle or farmstead, need to be understood and situations where strongly vertical cuttings form part of the feature of interest studying the point cloud in addition to the surface model can be productive.

Closely related to the discussion below on Communication Issues, while the visualizations effective for reading DTMs and DSMs are largely agreed upon, as are the effect of various parameters e.g. light source direction, hillshade altitude, number of segments in a sky view factor calculation, the effects of light source, view angle, icon size, view clipping, or color schemes on point cloud visualizations remain poorly studied. The development of a methodology for the representation of standing archaeological remains and surface topography in point cloud data represents a necessary next step, as archaeologists use it to study increasingly complex remains and landscape areas.

\section{Second Level Methodological Development}

\section{Integration with Fieldwork}

Perhaps the most important development in the use of ALS in archaeology in recent years is the increasing use of primarily_raster visualizations in fieldwork (Fig. 3). Both Heritage Management agencies, e.g. Historic England (formerly English Heritage) and research projects, e.g. The Survey and Landscape Archaeology on Montserrat (SLAM) Project, are using ALS visualizations to guide fieldwork. For Historic England, in internal projects like the study of the miner-farmer landscapes in the North Pennines (Ainsworth et al. 2013; Schindling and Gibbes 2014), archaeologists took ALS visualizations into the field on tablets or paper, using the data to guide the in-person interpretation of landscape features in an uplands former industrial region. For the SLAM Project (Cherry et al. 2012; Ryzewski and Cherry 2015; Opitz et al. 2015) the ALS visualizations primarily guided both the planning of the survey in terms of areas to visit on the ground. As in the Pennines, ALS visualizations were taken into the field, and aided in the identification of more subtle landscape features.

\section{Fig. 3}

Fieldwork in Montserrat (left) and Chailluz (right) involves bringing visualizations of the ALS data into the field. This practice allows direct visual comparison between features seen on the ground and those recognized in the data. (Image Credits: Cherry and Ryzewski—SLAM Project and Daval-LIEPPEC) 


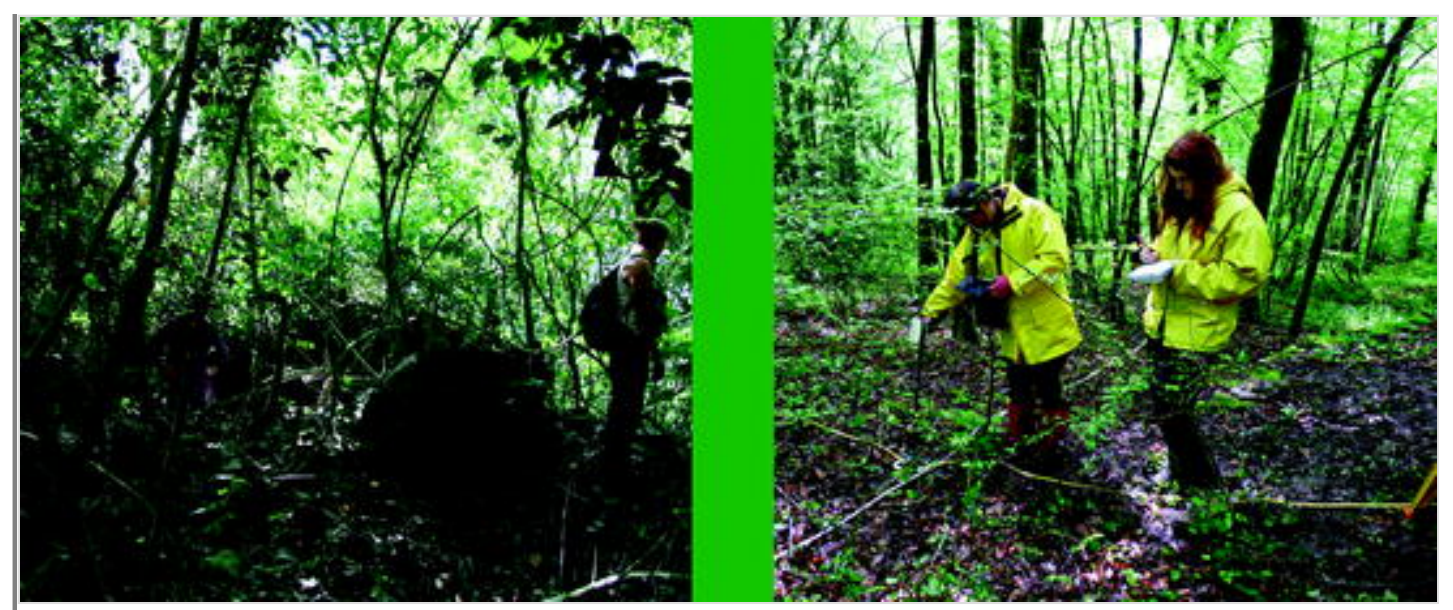

AQ3

These two projects can be used as examples of quite different fieldwork engagements with ALS data. For the Pennines Project, the field archaeologists using ALS imagery were already familiar with the territory and had spent substantial time on the ground. This, then, is a situation of 'new eyes' with ALS visualizations helping field archaeologists to see a relatively familiar landscape in new ways. The unfamiliar look of ALS becomes beneficial in many ways, forcing visual attention on areas of a known region that might otherwise be missed. Further, the 'overview' character of an ALS visualization can aid archaeologists in the field in recognizing extensive micro-relief features, particularly in open areas, and this is one of the main contributions of the technology for projects like the that in the Pennines (Ainsworth et al. 2012).

The archaeologists in the field with the SLAM Project face a very different situation. Because of the extremely difficult conditions on the ground, dominated by relatively young tropical forest, rugged and steeply sloping terrain, and boulder fields and unusual geological formations due to recent volcanic activity, ALS visualizations first and foremost were used to target on-the-ground survey. The archaeologists on this project do not have the benefit of long periods in the landscape because of its inaccessibility. Further, while there is a well-established visual and mental template of features likely to be seen in an English landscapes and what they look like in aerial imagery, no such template exists for the colonial landscape of Montserrat. As a relatively young project in a nation without a substantial history of landscape survey or aerial image interpretation, the starting point for the reading of ALS while in the landscape is quite different. Visual 'clutter' when working on the ground, including complex patterns of light and shadow, dense vegetation and surface scatters readily obscure more subtle micro-topographic features. Consequently, the kinds of features identified using the ALS visualizations were different (Opitz et al. 2015).

These projects are representative of the use of ALS under quite different circumstances. They illustrate the general trend toward an on-the-ground engagement with ALS visualizations, and a continued blurring between what once were the distinctly separate worlds of desk-based work and fieldwork, and of heads-up interpretation of aerial imagery on the one hand and field interpretation of topography on the other.

\section{Communication Issues: Aerial Imagery Interpretation, Dynamic Visualizations and the Retreat from the Hachure Plan}

Archaeology of the scientific bent, as practiced today, values the publication of data and a clear explanatory chain detailing how one arrived at an interpretation based on that data. The interpretation of ALS sits somewhat uncomfortably in this respect, as the precise and detailed metric models carry an air of the scientific, and the publication of the data itself is reasonably common practice, but the interpretation is purely visual and individual. Like the identification of a ceramic sherd or lithic tool by an expert, photos and drawings can be published, but the interpretation and identification of the type of object remains only loosely linked to these. But where the need for specialist expertise is broadly recognized for 
the identification of ceramics or lithics, the reading of aerial imagery is often treated as self-evident (thanks in some small part to the prevalence of google maps \& co., bringing aerial imagery to the general public). The hachure plan through which topographic data was communicated prior to the advent of lidar, much like the drawing of a lithic fragment or ceramic sherd, had the interpretation pre-packaged, and this reified communication of form was not really questioned. After all, you would have to go to the place and take detailed measurements yourself, a laborious process, to produce a new plan with which to question the extant one. In most cases the shape of the thing was its shape. The multitude of techniques used to visualize ALS terrain models, and the open discussion within the practitioner community about their relative merits and the difficulties of features that 'appear' and 'disappear' in different visualizations, has created a situation in which the visual interpretation is always up for debate. The all too evident ease with which the visual appearance of different shapes is manipulated means an expert's interpretation is readily questioned. The shape of a terrain feature, as seen in the ALS terrain model, shaded in some way, is not necessarily its shape. Further, we cannot simply retreat to just showing the 'raw' terrain model, as it is clear that many real features are only recognizable when visualized in certain ways. So what to do when trapped between the good and bad of data projections and visualizations? They are sometimes the only thing that shows up the real archaeology, but they are also the primary source of visual artifacts and illusions. The answer brings us back to expertise, and the expert interpreter's ability to choose an appropriate visualization technique and differentiate between real features and illtsionaryillusory ones.

In practice, most expert interpreters use multiple terrain model visualizations side-by-side to make an interpretation. The appearance or absence of a feature in any given visualization provides additional information. It is this collection of visual impressions that results in a final identification and interpretation. In conclusion, in spite of the highly metric and precise nature of ALS data and models derived from it, it is unreasonable to ask for a scientific-style chain of evidence from data to interpretation, because dynamic viewing and visual impression sit squarely in the middle of the process. But having left the reified topographic language of the hachure plan behind in favor of a dynamic suite of terrain visualizations, the inherent problem of interpretation based on visual gestalt — an issue not limited to ALS — is pushed to the fore.

\section{Beyond Methodology}

\section{Topography as Archaeological Information: Reading the Impact of Recent Land Use}

Any archaeological feature recognized in ALS data is viewed in the context of the contemporary landscape, and the impacts of current or recent land use are often abundantly apparent. Barrows are seen in and out of ploughed fields and limekilns are seen in and out of the forest. The effect of mechanized agriculture, in particular deep ploughing as practiced in much of Europe, while bringing buried ceramics and building materials to the surface and creating a golden age for fieldwalking survey, caused evident deterioration to topographic features (Darvill 2014). This is most evident when single features are located on a border between land use zones, as a direct comparison can be made. Even where direct comparison is not available, the general appearance of a class of features of which there are many scattered across the landscape which are likely from roughly the same period allows for the impact of subsequent land use to be assessed. This situation opens the possibility for a close study of the impacts of management on earthwork and topographic features of various types.

The afforestation of areas under plough until the first half of the 20th century and then abandoned after a population decline or transfer have the converse effect, resulting in pockets of unusually well preserved remains of the 18th and 19th centuries. (Though some forest management practices are as destructive to archaeological topography as ploughing; see Crow 2004) Separately, it provides the means to engage with a landscape archaeology of the recent past. The later of these has already begun, primarily by archaeologists working on WWI and WWII landscapes (e.g. Hesse 2014; Gheyle et al. 2014), whose entrenchments, battlegrounds, and abandoned towns can be found in well preserved states within today's forests. While this work has primarily been carried out in an European sphere, the potential for new work 
in the archaeology of the recent past, taking advantage of excellent preservation and visibility afforded by ALS data collection in woodlands, exists across almost all regions where data is now being acquired.

\section{Topography as Archaeological Information: Interpreting Other 'scrapes' in the Landscape}

In the European context, where topographic survey has the longest history, we may divide traditional interest in archaeological topography into three areas: monumental earthworks, e.g. mounds, barrows, ring-forts; extensive organized features i.e. field boundaries; and standing monuments e.g. ruined cities and estates (as an instructive example, see Collis 2013 ). In Northern Europe monumental earthworks have been particularly dominant, particularly in the discourse on prehistoric landscapes and settlement, while the Classical Mediterranean region developed a strong tradition of survey of standing monuments in urban contexts. The uptake in use of ALS has encouraged archaeologists to move outside these areas of study and pay attention to the topographic signatures of a much wider variety of features. These features generally are smaller in size, and related to the economy and use of the forests themselves, or other aspects of the rural economy. Thus we have a proliferation of studies incorporating or depending primarily on mapping and characterization of limekilns, charcoal burning platforms, surface quarries, animal trapping pits, field clearance cairns, and ditches, with which we can build a picture of the rural landscape (Fig. 4). Raab et al. (2015), in their work using ALS regional survey data processed by the state heritage agency, specifically point to the enormous quantity of small topographic features, charcoal burning platforms in southeast Germany being a case in point, as calling for another form of interpretation, as the distribution of these features and their emplacement in the landscape is of interest, rather than any single feature.

Fig. 4

Charcoal burning platforms and other evidence of rural economic activity, seen in the lidar data from the Besançon lidar survey. Data kindly provided by the LIEPPEC Project, Université de Franche-Comté

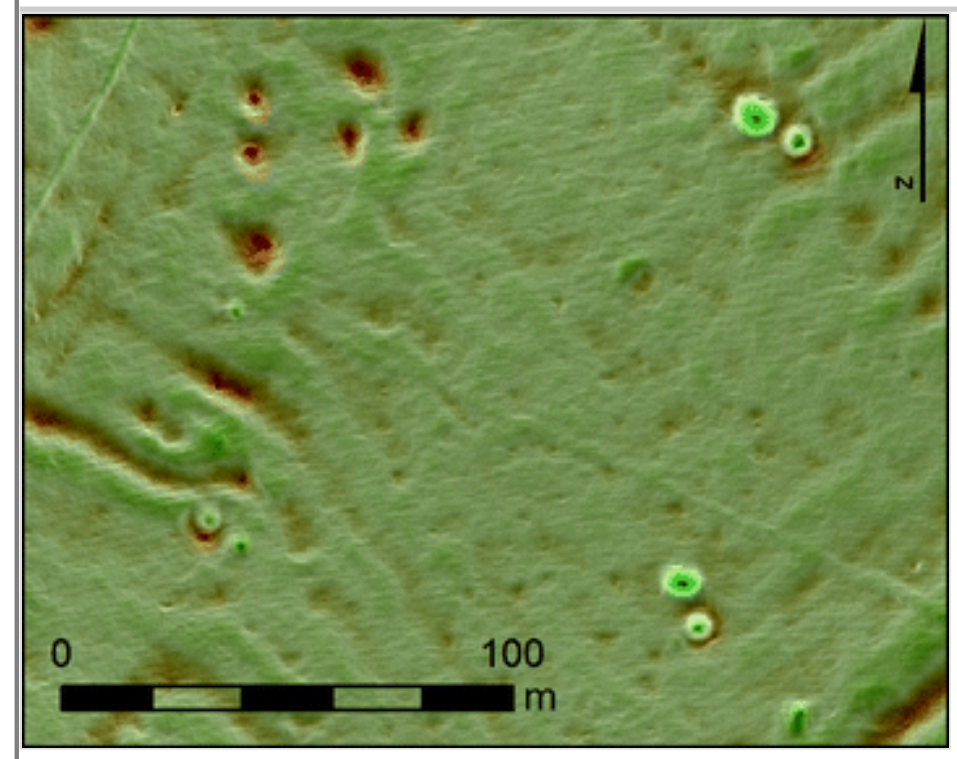

The shift in focus from the individual monument or organized system of features to the dense palimpsest of small features reflects both the character of the ALS data and the coincidence of its development in parallel with the rise of landscape archaeology as a theoretical approach. Along these lines, Mlekuž offers several papers reflecting on topics from braided hollow ways representing fluctuating routeways, to collections of kilns, charcoal burning platforms, and natural karstic depressions forming complex landscape assemblages (2012, 2013). Mlekuž, among others, emphasizes the use of lidar to look not just at a single feature or collection of features, but to tie more closely together the features and the landscape 
in which they are embedded, referring to the remains of various activities as 'scrapes' in the landscape (Mlekuž 2012). The expansion to look at all the activity, all the 'scrapes', in the landscape provides a means of tracking the intensity of activity over time, in a general sense.

While we can speak broadly about trends in the intensity of activity based on a broad look at all the features appearing in the landscape associated with a given activity or activities, in engaging with the many 'scrapes' of a densely inscribed archaeological landscape, the perennial problem of establishing even a relative chronology remains. Mlekuž's work on hollow ways illustrates the constant cutting and re-cutting of these paths, seemingly seasonally or ad hoc, resulting in a buildup of archaeological features. This kind of sequence highlights the perhaps obvious fact that a relatively large number of archaeologically visible events does not necessarily equate to a long time period, and the difficulties that can arise in reading the succession of cuts and overlays from the topographic data.

\section{Topography as Archaeological Information: Diffuse Urbanism in Neo-tropical Rainforests}

The advent of ALS for archaeological projects studying the phenomenon of urbanism in now heavily forested regions of Central and South America and Southeast Asia has resulted in a substantially improved understanding of the structure of these cities. Notably, survey results show that 'diffuse' urban areas are more extensive than previously thought. In some cases, the suburban and ex-urban surroundings of the densely urbanized core stretch almost to the limits of the ex-urban zone around another city. The scale of urbanized areas was extremely difficult to grasp prior to the use of lidar, due to the poor visibility and difficulties of accessibility on the ground in dense jungle environments. In addition to the shift in scale, the details of the patterns of occupation outside the dense cores of these cities are emerging through systematic study of the topographic models, combined with targeted survey work on the ground. Notable projects working on this topic include the Cambodia Archaeological Lidar Initiative ( http://angkorlidar.org/), whose study areas include Ankor Wat, Sambor Prei Kuk, Koh Ker, and Phnom Kulen (Evans et al. 2013), studies of Caracol in Belize, led by Chase and Chase (Chase et al. 2011), and work at Angamuco in Mexico by Fisher (Fisher and Leisz 2013). A discussion of the impacts of ALS on this area of study can be found in Chase et al. (2012) wherein they note that lidar data, "are changing commonly held interpretations of societal development profoundly." as, "[t]he more complete LiDAR data demonstrate that some ancient Mesoamerican sites are far more extensive and complex than was thought possible following popular sociopolitical models". For questions of diffuse urbanism, the large scale at which ALS data allows archaeologists to observe patterns in detail is crucial. As surveys in these regions rapidly proliferate, the impact of the availability of ALS as a tool for rapid mapping of sprawling built up areas will continue.

\section{Conclusions}

Over the past decade ALS has become an important archaeological survey technique, used in a variety of landscape and regional scale research and heritage management projects. The methodology used to analyze and interpret ALS data has matured, and the general approach is now widely agreed upon. Archaeology is seeing a rapid democratization of the use of this data, and methodological development to treat difficult landscapes or classes of features continues as the use of ALS proliferates. Outside of the cases where basic methodological work is still needed to improve archaeological visibility, notably in areas dominated by low scrub or a profusion of objects on the surface, the main methodological developments are now focused on the combination of LiDAR and field survey to improve the interpretation of broad areas of landscape and accelerate landscape and regional survey.

The majority of archaeological research projects or Heritage Management schemes employing ALS continue to be found in Northern and Western Europe (Opitz and Cowley 2012), unsurprising as much early work with archaeological ALS was carried out in these regions. However, the success of ALS in elucidating urban plans in tropical forest regions such as at El Caracol in Belize and other Mesoamerican sites (Chase et al. 2011), and the increasing availability of and growing interest in the publicly-accessible USGS LiDAR data in the United States (Pluckhahn and Thompson 2012; 
Randall 2014) are encouraging the use of ALS in these regions. While the method has spread from its roots in Europe to use in the Americas and Southeast Asia, its use for archaeological survey in Africa, where forest dominates large swathes of landscape, and much of Asia, where land cover also obscures much of the archaeological landscape, has not yet begun. The adaptation of archaeological ALS methods to the ground conditions and research questions relevant in these places is an area with great future potential.

Reflecting on more than a decade of increasing research activity, the greatest impacts of ALS are that by allowing archaeologists to more efficiently survey expansive regions obscured by woodland or scrub vegetation, ALS has reintegrated these areas into research based on regional survey data, and by opening forests to systematic study it has reinvigorated lines of research focused explicitly on archaeology in woodlands. Even more exciting, the results of these surveys are beginning to support the study of broader regional patterns, allowing new approaches to fundamental questions on rural land use and economy, diffuse urbanism, and others yet to be explored.

\section{References}

Ainsworth, S., Oswald, A. and Went, D. (2013) Remotely acquired, not remotely sensed: using lidar as a field survey tool. In Opitz, R. S. and Cowley, D. C. (eds.) Interpreting Archaeological Topography. 3D Data, Visualisation and Observation. AARG Occasional Paper 5. Oxbow Books: Oxford, 206-22.

Axelsson, P., 1999. Processing of laser scanner data - algorithms and applications, ISPRS Journal of Photogrammetry and Remote Sensing, 54:138-147.

Bennett, R., Welham, K., \& Ford, A. (2012) A comparison of visualization techniques for models created from airborne laser scanned data. Archaeological Prospection, 19(1), 41-48.

Brodu, N., \& Lague, D. (2012) 3D terrestrial lidar data classification of complex natural scenes using a multi-scale dimensionality criterion: Applications in geomorphology. ISPRS Journal of Photogrammetry and Remote Sensing, 68, $121-134$.

Chase, A. F., Chase, D. Z., Fisher, C. T., Leisz, S. J., \& Weishampel, J. F. (2012) Geospatial revolution and remote sensing LiDAR in Mesoamerican archaeology. Proceedings of the National Academy of Sciences, 109(32), 1291612921.

Chauve, A., Mallet, C., Bretar, F., Durrieu, S., Deseilligny, M. P., \& Puech, W. (2007) Processing full-waveform lidar data: modelling raw signals. In International archives of photogrammetry, remote sensing and spatial information sciences 2007, 102-107.

Cherry, J. F., Ryzewski, K., \& Leppard, T. P. (2012) Multi-period landscape survey and site risk assessment on Montserrat, West Indies. The Journal of Island and Coastal Archaeology, 7(2), 282-302.

Collis, J. (2013) The Development of Archaeological Thought as Evidenced in theYorkshire Archaeological Journal. Yorkshire Archaeological Journal 2013; 85(1), 5-26.

Darvill, T. (2014) Ancient monuments in the countryside: an archaeological management review. English Heritage Publishing.

Evans, D. H., Fletcher, R. J., Pottier, C., Chevance, J. B., Soutif, D., Tan, B. S.,\& Boornazian, G. (2013) Uncovering 
archaeological landscapes at Angkor using lidar. Proceedings of the National Academy of Sciences, 110(31), 1259512600.

Fisher, C. T., \& Leisz, S. J. (2013) New Perspectives on Purépecha Urbanism Through the Use of LiDAR at the Site of Angamuco, Mexico. In Mapping Archaeological Landscapes from Space (pp. 199-210) Springer New York

Hesse, R. (2010) LiDAR-derived Local Relief Models-a new tool for archaeological prospection. Archaeological Prospection, 17(2), 67-72.

Hesse, R. (2014) Geomorphological traces of conflict in high-resolution elevation models. Applied Geography, 46, 1120.

Gheyle, W., Dossche, R., Bourgeois, J., Stichelbaut, B., \& Van Eetvelde, V. (2014) Integrating Archaeology and Landscape Analysis for the Cultural Heritage Management of a World War I Militarised Landscape: The German Field Defences in Antwerp. Landscape Research, 39(5), 502-522.

Kokalj, Z., Zaksek, K., \& Ostir, K. (2011) Application of sky-view factor for the visualisation of historic landscape features in lidar-derived relief models.Antiquity, 85(327), 263-273.

Mlekuž, D. (2012) Messy landscapes: lidar and the practices of landscaping. In Opitz and Cowley...In Opitz, R.S. and D.C. Cowley (eds.) Interpreting archaeological topography: Lasers, 3D data, observation, visualisation and applications, AARG Occassional Paper 5. 90-101. Oxford: Oxbow Books.

Mlekuž, D. (2013) Skin Deep: LiDAR and Good Practice. In C. Corsi, B. Slapsak, and F. Vermeulen. Good Practice in Archaeological Diagnostics: Non-invasive Survey of Complex Archaeological Sites, 113:-129. New York, Dordrecht and London: Heidelberg.

Nex, F., \& Remondino, F. (2014) UAV for 3D mapping applications: a review.Applied Geomatics, 6(1), 1-15.

Opitz, R., \& Limp, F. (2015) Recent Developments in HDSM for Archaeology: Implications for Practice and Theory. Annual Review of Anthropology, 44(1).

Opitz, R., \& Nuninger, L. (2014) Point Clouds Segmentation of Mixed Scenes with Archeological Standing Remains: A Multi-Criteria and Multi-Scale Iterative Approach. International Journal of Heritage in the Digital Era, 3(2), $287-$ 304.

Opitz, R., Ryzewski, K., Cherry, J. and Moloney, B. (fortheoming, 2015) Using Airborne LiDAR Survey to explore Historic-era archaeological landscapes of Montserrat in the Eastern Caribbean. Journal of Field Archaeology, 41(1): 523-541.

Pluckhahn, T. J., and Thompson, V. (2012) Integrating LiDAR Data and Conventional Mapping of the Fort Center Site in South-Central Florida: A Comparative Approach, Journal of Field Archaeology 37(4): 289-301.

Raab, A., Takla, M., Raab, T., Nicolay, A., Schneider, A., Rösler, H., \& Bönisch, E. (2015) Pre-industrial charcoal production in Lower Lusatia (Brandenburg, Germany): detection and evaluation of a large charcoal-burning field by combining archaeological studies, GIS-based analyses of shaded-relief maps and dendrochronological age determination. Quaternary International,367, 111-122. 
Randall, A. R. (2014) LiDAR-aided Reconnaissance and Reconstruction of Lost Landscapes: An Example of Freshwater Shell Mounds (ca. 7500-500 CAL B.P.) in Northeastern Florida, Journal of Field Archaeology 39(2): 162-179.

Ryzewski, K., \& Cherry, J. F. (2015) Struggles of a Sugar Society: Surveying Plantation-Era Montserrat, 1650-1850. International Journal of Historical Archaeology, 19(2), 356-383.

Schindling, J., \& Gibbes, C. (2014) LiDAR as a tool for archaeological research: a case study. Archaeological and Anthropological Sciences, 6(4), 411-423.

Štular, B., Kokalj, Ž., Oštir, K., \& Nuninger, L. (2012) Visualization of lidar-derived relief models for detection of archaeological features. Journal of Archaeological Science, 39(11), 3354-3360.

Watts, A. C., Ambrosia, V. G., \& Hinkley, E. A. (2012) Unmanned aircraft systems in remote sensing and scientific research: Classification and considerations of use. Remote Sensing, 4(6), 1671-1692. 